\title{
Long-term exposure to pemetrexed induces chronic renal dysfunction in patients with advanced and recurrent non- squamous cell lung cancer: a retrospective study
}

Kengo Umehara ${ }^{1}$, Kaori Yama ${ }^{2 *}$, Nozomi Koike ${ }^{2}$, Shintarou Takayama ${ }^{3}$, Azusa Wakamoto ${ }^{4}$, Tae Hatuyama ${ }^{4}$, Michiya Kobayashi ${ }^{5}$ and Hideki Sato ${ }^{2}$

\begin{abstract}
Background: Pemetrexed (PEM) is administered over a long term to patients with non-squamous cell lung cancer as a maintenance therapy after platinum combination induction chemotherapy. Although decreased renal function owing to long-term PEM exposure has been reported, changes in the renal function of individual patients have not been reported. This study aimed to evaluate serum creatinine ( $\mathrm{Scr}$ ) in individual patients over time and determine whether long-term PEM exposure contributed to increased Scr.
\end{abstract}

Methods: A retrospective study was performed using 90 non-squamous cell lung cancer patients, who had received maintenance therapy with $\mathrm{PEM} \pm$ bevacizumab (BEV) after carboplatin $+\mathrm{PEM} \pm \mathrm{BEV}$ therapy at the Sapporo Minami-Sanjo Hospital from February 2012 to February 2019. Using Scr at the start of induction chemotherapy as the baseline, we calculated the correlation coefficient $(r)$ of the rate of Scr change in an individual patient and the number of treatment courses to divide patients into two groups for comparison: patients with + $0.4<r \leqq+1.0$ and an observed positive correlation (the $r_{+0.4<}$ group), and patients with $-1.0 \leqq r \leqq+0.4$ and no observed positive correlation (the $r_{+0.4 \geqq}$ group).

Results: Statistically significant differences between the $r_{+0.4<}$ group and the $r_{+0.4 \geqq}$ group were observed for the following parameters: the median cumulative dose of PEM (interquartile range) $[9100(6365,12,260) \mathrm{mg} / \mathrm{body}$ vs. $5600(4140,7440) \mathrm{mg} / \mathrm{body}, P<0.01]$; the number of patients taking nonsteroidal anti-inflammatory drugs at the start of treatment $[15$ patients (31\%) vs. 3 patients $(7 \%), P<0.01]$; and the median number of treatment courses starting from induction chemotherapy $[11(8,14)$ courses vs. $8(6,11)$ courses, $P<0.01]$. Next, the results of univariate and multivariate analyses demonstrated that the cumulative dose of PEM $(\geqq 7000 \mathrm{mg} / \mathrm{body}$ vs $<7000$ $\mathrm{mg} / \mathrm{body}, \mathrm{OR} 2.40 ; 95 \% \mathrm{Cl}, 1.22-4.75, P=0.01$ ) was an independent explanatory variable of the $r_{+0.4<}$ group.

(Continued on next page)

\footnotetext{
* Correspondence: yama-k@hus.ac.jp

${ }^{2}$ Division of Clinical Pharmacy, Department of Pharmacy, Faculty of

Pharmaceutical Sciences, Hokkaido University of Science, 15-4-1 Maeda 7,

Teine-ku, Sapporo 006-8585, Japan

Full list of author information is available at the end of the article
}

(C) The Author(s). 2020 Open Access This article is licensed under a Creative Commons Attribution 4.0 International License, which permits use, sharing, adaptation, distribution and reproduction in any medium or format, as long as you give appropriate credit to the original author(s) and the source, provide a link to the Creative Commons licence, and indicate if changes were made. The images or other third party material in this article are included in the article's Creative Commons licence, unless indicated otherwise in a credit line to the material. If material is not included in the article's Creative Commons licence and your intended use is not permitted by statutory regulation or exceeds the permitted use, you will need to obtain permission directly from the copyright holder. To view a copy of this licence, visit http://creativecommons.org/licenses/by/4.0/ The Creative Commons Public Domain Dedication waiver (http://creativecommons.org/publicdomain/zero/1.0/) applies to the data made available in this article, unless otherwise stated in a credit line to the data. 
(Continued from previous page)

Conclusions: Long-term PEM exposure may induce chronic renal dysfunction. Hence, maintaining kidney function during PEM treatment by reducing the use of combination drugs and the risk of other renal dysfunctions, such as dehydration, may help patients continue therapy and contribute to their long-term survival.

Keywords: Pemetrexed, Contribution maintenance, Chronic kidney disease, Lung cancer

\section{Background}

The antifolate drug pemetrexed (PEM) is known to demonstrate a powerful antitumor effect against tumor cells in mesothelioma and non-small-cell lung cancer by inhibiting multiple folate-metabolizing enzymes simultaneously [1]. The JMDB trial comparing PEM + cisplatin therapy with gemcitabine + cisplatin therapy for nonsmall-cell lung cancer has demonstrated non-inferiority [2], and investigation of survival time by tissue type has demonstrated that patients with non-squamous cell cancer reported a significantly longer survival time [3]. Furthermore, Paz-Ares et al. have reported that the continued administration of PEM as a maintenance therapy significantly extended progression-free survival in patients who have efficaciously been treated with PEM + cisplatin induction chemotherapy in the PARAMOUNT trial [4]. Additionally, the final report of the PARAMOUNT trial in 2013 has stated that PEM maintenance therapy for advanced nonsquamous non-small-cell lung cancer extends overall survival [5].

The primary elimination pathway of PEM in the body is renal excretion through tubular secretion and glomerular filtration. Therefore, patients demonstrating decreased renal function are at a risk of increased blood PEM concentrations associated with decreased PEM clearance [6], as well as exacerbated side effects related to PEM, including liver dysfunction, rash, leukopenia, neutropenia, loss of appetite, decreased hemoglobin, and nausea [7]. Additionally, some studies have indicated nephrotoxicity attributed to PEM. Regarding the possible mechanism, it is postulated that PEM enters the cells via both the folate receptor alpha transporters on the luminal surface of proximal renal tubular epithelial cells and the reduced folate transporters on the basolateral surface of the same cells, after which PEM undergoes polyglutamation [8]; then, the affinity for folatemetabolizing enzymes increases and folate metabolism is suppressed, resulting in renal tubular cell dysfunction [9]. In clinical practice, reports of renal dysfunctions due to PEM administration include acute kidney injury, due to acute tubular necrosis [10], as well as nephrogenic diabetes insipidus and renal tubular acidosis [11].

Since the final report of the PARAMOUNT trial [5] in 2013, several patients have received PEM maintenance therapy and the number of patients administered longterm PEM has been increasing. Several studies have examined the changes in the renal function of patients undergoing PEM maintenance therapy. Chen et al. have reported that the estimated creatinine clearance [Ccr $(\mathrm{mL} / \mathrm{min})]$ helps predict the efficacy and toxicity of PEM maintenance therapy [12]. Furthermore, Middleton et al. have indicated that renal events leading to the suspension or postponement of PEM administration are related to an increase in serum creatinine (Scr) by at least $30 \%$ [13]. In addition, Visser et al. have reported that there is a risk of kidney dysfunction during PEM maintenance therapy [14]. However, these studies failed to investigate the changes in the renal function of individual patients, and there are currently no studies investigating chronic renal failure in patients administered long-term PEM. We performed a retrospective study in patients with non-squamous cell lung cancer who had received PEM + platinum formulation \pm bevacizumab (BEV) induction chemotherapy and were successfully transitioned to maintenance therapy at the Sapporo Minami-Sanjo Hospital. The objective was to evaluate the Scr of individual patients over time and determine whether long-term PEM exposure contributes to increased Scr.

\section{Methods}

\section{Subjects}

We performed a retrospective study of 90 patients with advanced, metastatic non-squamous cell lung cancer patients who had transitioned to maintenance therapy every 3 weeks using PEM $\left(500 \mathrm{mg} / \mathrm{m}^{2}\right.$, day 1$)$ with or without $\mathrm{BEV}(15 \mathrm{mg} / \mathrm{kg}$, day 1$)$, after induction chemotherapy every 3 weeks using carboplatin (CBDCA; AUC 5 , day 1$)$ and PEM $\left(500 \mathrm{mg} / \mathrm{m}^{2}\right.$, day 1$)$ with or without $\operatorname{BEV}(15 \mathrm{mg} / \mathrm{kg}$, day 1$)$ at the Sapporo Minami-Sanjo Hospital between February 1, 2012, and February 28, 2019. Ccr is defined as at least $45 \mathrm{~mL} / \mathrm{min}$ at the starting criterion for PEM, and the Ccr of all patients at the first dose of PEM was greater than $45 \mathrm{~mL} / \mathrm{min}$. Vitamin B12 (cyanocobalamin $1000 \mu \mathrm{g}$, intramuscular injection, every 9 weeks) and folic acid ( $0.5 \mathrm{mg}$ orally once per day, every day) were administered to all patients to prevent side effects during induction or maintenance chemotherapy, along with dexamethasone tablets $(4 \mathrm{mg}$ orally once per day on days 2-4) to prevent rashes. The study period was from the start of induction chemotherapy until a point during the maintenance therapy when the patient's condition exacerbated, or unacceptable toxicity occurred, 
or the patient or the physician decided to discontinue treatment.

\section{Data collection}

In this retrospective study, we used the physician's electronic medical chart, nursing records, drug administration instruction records, and ordering systems to determine sex, smoking history, age at the start of induction chemotherapy, disease stage based on the 7th Edition of the UICC TNM Classification of Malignant Tumors, tissue type based on the 8th Edition of the Japan Lung Cancer Society Rules for the Treatment of Lung Cancer, the Eastern Cooperative Oncology Group Performance Status (ECOG-PS), the presence of complications (diabetes, hypertension, and hyperlipidemia), body surface area $\left(\mathrm{m}^{2}\right)$ calculated using the DuBois formula (formula 1), kidney function parameters [estimated glomerular filtration rate (GFR) calculated using the GFR estimation formula for Japanese people (eGFR, $\mathrm{mL} / \mathrm{min} / 1.73 \mathrm{~m}^{2}$ ) (formula 2), eGFR uncorrected for body surface area $(\mathrm{mL} / \mathrm{min})$, estimated Ccr calculated using the Cockcroft-Gault formula $(\mathrm{mL} / \mathrm{min})$ (formula 3), Scr using the enzyme method ( $\mathrm{mg} /$ $\mathrm{dL}$ )], the presence of central nervous system metastasis, and the concomitant use of drugs reported to affect kidney function [nonsteroidal anti-inflammatory drugs (NSAI Ds), angiotensin II receptor blockers (ARB), angiotensinconverting-enzyme inhibitors (ACEI), aminoglycosides, and proton-pump inhibitors (PPI)]. Additionally, the total number of treatment courses from induction chemotherapy to maintenance therapy and the cumulative dose of anticancer drugs (mg/body) were assessed.

(Formula 1) Body surface area $\left(\mathrm{m}^{2}\right)=0.007184 \times$ body weight $^{0.425} \times$ height $^{0.725}$

$\left(\right.$ Formula 2) eGFR $\left(\mathrm{mL} / \mathrm{min} / 1.73 \mathrm{~m}^{2}\right)=194 \times \mathrm{Scr}^{-1.094}$ $\times \operatorname{age}^{-0.287}(\times 0.739$ for women $)$

(Formula 3) Estimated Ccr $(\mathrm{mL} / \mathrm{min})=[(140-$ age $) \times$ body weight $/(72 \times$ serum creatinine $)](\times 0.85$ for women $)$

\section{Assessments}

The correlation coefficient $(r)$ was used to evaluate the relationship between two variables, the Scr at the start of each treatment course in an individual patient and the number of treatment courses. Overall survival (OS) was defined as the period from the start of induction chemotherapy until the date of death or until the final day of the study period, February 28, 2019. Adverse events were determined according to the National Cancer Institute Common Terminology Criteria for Adverse Events Version 4.0.

\section{Statistical analysis}

We used Spearman's rank correlation coefficient to determine $r$, using the two variables, Scr at the start of each treatment course and the number of treatment courses. In this study, correlation coefficients were used to assess the relationship between cumulative PEM dosage as a temporal factor, and chronic renal dysfunction. The correlation strength was interpreted based on the size of the absolute value of $r$, and the following general standards were commonly used: $0.0 \leqq|r| \leqq 0.2$ : almost no correlation; $0.2 \leqq|r| \leqq 0.4$ : weak correlation; $0.4 \leqq|r| \leqq 0.7$ : considerable correlation; and $0.7 \leqq|r| \leqq 1.0$ : strong correlation. The present study divided patients into two groups based on $r$ : (1) those in whom a significant difference, positive correlation was observed ( $+0.4<r \leq+1.0$; the $r_{+0.4<}$ group) corresponding to a considerable or strong correlation and (2) those in whom no positive correlation was observed $(-1.0$ $\leq r \leq+0.4$; the $r_{+0.4 \geq}$ group). A significance level of less than $5 \%$ was considered statistically significant in all tests. Background information regarding the patients in the two groups was compared using the chi-squared test for measurements on a nominal scale and the Fisher exact test for measurements with an expected frequency of less than five. The Student $t$ test was used for measurements whose homoscedasticity could be assumed according to a normal distribution, while the Welch $t$ test was used for measurements whose homoscedasticity could not be assumed according to normal distribution. Additionally, the MannWhitney $U$ test was performed for measurements on an ordinal scale with a non-normal distribution. The OS was estimated using a Kaplan-Meier curve, and the groups were compared using the log-rank test. Among factors demonstrating a significance level of less than $5 \%$ in a comparison between the two groups, for the factors on the ordinal scale, we calculated the predictive ability of the presence of a positive correlation and the cutoff value using a receiver operating characteristic (ROC) curve by converting to a nominal scale. Multivariate and univariate analyses were performed using binomial logistic regression analysis, and the odds ratio (OR) was determined. Statistical analyses were performed using the Bell Curve for Excel software (Social Survey Research Information Co., Ltd., Tokyo).

\section{Ethical considerations}

This study was approved (approval no. 25-1) by the ethical review board of the Sapporo Minami-Sanjo Hospital in accordance with the Ethical Guidelines for Medical and Health Research Involving Human Subjects. Additionally, the study carefully protected personal information and anonymized all data used. Information about this study was made available on Sapporo Minami-Sanjo Hospital website to ensure that patients had the opportunity to refuse participating in the study.

\section{Results}

\section{Patient background information}

Table 1 presents the background information for the 90 subjects included in this study. There were $56(62 \%)$ 
Table 1 Comparison of patient background and correlation coefficient $+0.4<$ group and correlation coefficient $+0.4 \geqq$ group

\begin{tabular}{|c|c|c|c|c|c|}
\hline & All, $N=90$ & $r_{+0.4<\prime} N=49$ & $r_{+0.4 \geqq \prime} N=41$ & $P$ & \\
\hline Gender, N (\%) & Men / women & $56(62) / 34(38)$ & $31(63) / 18(37)$ & $25(61) / 16(39)$ & $0.82^{\mathrm{a})}$ \\
\hline Age, median (interquartile range) & & $68(63,74)$ & $68(62,73)$ & $68(63,74)$ & $0.51^{b)}$ \\
\hline \multirow[t]{2}{*}{ Histological type, $N(\%)$} & adenocarcinoma & $86(96)$ & $47(96)$ & $39(95)$ & $0.62^{\mathrm{a})}$ \\
\hline & $\begin{array}{l}\text { malignant pleural } \\
\text { mesothelioma }\end{array}$ & $4(4)$ & $2(4)$ & $2(5)$ & \\
\hline \multirow[t]{2}{*}{ Stage, N (\%) } & $\| \mathrm{A}$ and $\| \mathrm{B}$ & $27(30)$ & $17(35)$ & $10(24)$ & $0.56^{\mathrm{a})}$ \\
\hline & IV and recurrence & $63(70)$ & $32(65)$ & $31(76)$ & \\
\hline \multirow[t]{2}{*}{ Performance status, $N(\%)$} & 0 and 1 & $85(95)$ & $45(92)$ & $40(97)$ & $0.42^{\mathrm{a})}$ \\
\hline & 2 and 3 & $5(5)$ & $4(8)$ & $1(3)$ & \\
\hline \multirow[t]{2}{*}{ Smoking history, N (\%) } & no smoking and current & $69(77)$ & $34(69)$ & $35(85)$ & $0.07^{\mathrm{a})}$ \\
\hline & never & $21(23)$ & $15(31)$ & $6(15)$ & \\
\hline \multicolumn{6}{|l|}{ Complications, N (\%) } \\
\hline Diabetes & YES / NO & $18(20) / 72(80)$ & $7(14) / 42(86)$ & $11(27) / 30(73)$ & $0.14^{\mathrm{a})}$ \\
\hline Hypertension & YES / NO & $37(41) / 53(59)$ & $19(39) / 30(61)$ & $18(44) / 23(56)$ & $0.62^{\mathrm{a})}$ \\
\hline Hyperlipemia & YES / NO & $9(10) / 81(90)$ & $4(8) / 45(92)$ & $5(12) / 36(88)$ & $0.39^{\mathrm{a})}$ \\
\hline $\begin{array}{l}\text { Body surface area }\left(\mathrm{m}^{2}\right) \text {, median } \\
\text { (interquartile range) }\end{array}$ & $1.60(1.48,1.72)$ & $1.63(1.49,1.79)$ & $1.59(1.46,1.68)$ & $0.33^{c)}$ & \\
\hline $\begin{array}{l}\text { eGFR }\left(\mathrm{ml} / \mathrm{min} / 1.73 \mathrm{~m}^{2}\right) \text {, median } \\
\text { (interquartile range) }\end{array}$ & $82(71,96)$ & $88(76,99)$ & $76(65,89)$ & $0.99^{b)}$ & \\
\hline $\begin{array}{l}\text { Estimated } \mathrm{Ccr}(\mathrm{ml} / \mathrm{min}), \text { median } \\
\text { (interquartile range) }\end{array}$ & $61(53,71)$ & $65(57,73)$ & $58(47,64)$ & $0.64^{b)}$ & \\
\hline $\mathrm{eGFR} \geqq 45,<60\left(\mathrm{ml} / \mathrm{min} / 1.73 \mathrm{~m}^{2}\right), N(\%)$ & $11(12)$ & $4(8)$ & $7(17)$ & $0.20^{a)}$ & \\
\hline $\operatorname{Scr}(\mathrm{g} / \mathrm{dl})$, median (interquartile range) & $0.6(0.6,0.8)$ & $0.6(0.5,0.8)$ & $0.7(0.6,0.8)$ & $0.82^{\mathrm{c})}$ & \\
\hline \multirow[t]{2}{*}{ Chemotherapy, N (\%) } & CBDCA+PEM+BEV & $72(80)$ & $37(76)$ & $35(85)$ & $0.24^{\mathrm{a})}$ \\
\hline & CBDCA+PEM & $18(20)$ & $12(24)$ & $6(15)$ & \\
\hline \multicolumn{6}{|l|}{ Concomitant drug, N (\%) } \\
\hline NSAIDs & YES / NO & $18(20) / 72(80)$ & $15(31) / 34(69)$ & $3(7) / 38(93)$ & $<0.01^{\mathrm{a})}$ \\
\hline ARB & YES / NO & $26(29) / 64(71)$ & $12(24) / 37(76)$ & $14(34) / 27(66)$ & $0.31^{\mathrm{a})}$ \\
\hline ACEI & YES / NO & $3(3) / 87$ (97) & $0(0) / 49(100)$ & $3(7) / 38(93)$ & $0.09^{a)}$ \\
\hline PPI & YES / NO & $30(33)$ / 60 (67) & $16(33) / 33(67)$ & $14(34) / 27(66)$ & $0.88^{\mathrm{a})}$ \\
\hline $\begin{array}{l}\text { Total number of treatments, median } \\
\text { (interquartile range) }\end{array}$ & $9(6,13)$ & $11(8,14)$ & $8(6,11)$ & $<0.01^{\mathrm{b})}$ & \\
\hline
\end{tabular}

CCr creatinine clearance, $S C r$ serum creatinine, CBDCA carboplatin, PEM pemetrexed, BEV bevacizumab, NSAIDs non-steroidal anti-inflammatory drugs, ARB angiotensin II receptor antagonist, $A C E I$ angiotensin converting enzyme inhibitor, $P P I$ proton pump inhibitor

a) Fisher's exact test

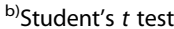

c) Mann-Whitney $U$ test

men and $34(38 \%)$ women subjects with a median age (interquartile range) of $68(63,74)$ years at the start of induction chemotherapy. The tissue type was adenocarcinoma in 86 patients (96\%) and malignant mesothelioma in 4 patients (4\%), with $27(30 \%)$ stage IIIA and IIIB patients and $63(70 \%)$ stage IV or recurrent patients. The ECOG-PS was 0 in 62 patients $(69 \%)$ and $1 \leqq$ in 28 patients (31\%). In terms of smoking history, 21 patients (23\%) were non-smokers and 69 (77\%) had either quit smoking or were smokers. Regarding the presence of complications, 18 patients (20\%) had diabetes, 37 (41\%) had hypertension, and 9 (10\%) had hyperlipidemia. The median (interquartile range) body surface area was 1.60 $(1.48,1.72) \mathrm{m}^{2}$. In the renal function parameters, the median eGFR was $82(71,96) \mathrm{mL} / \mathrm{min} / 1.73 \mathrm{~m}^{2}$, median eGFR uncorrected for body surface area was $75(66,87)$ $\mathrm{mL} / \mathrm{min}$, median Ccr was $61(53,71) \mathrm{mL} / \mathrm{min}$, and median Scr was $0.6(0.5,0.8)$. No patients developed severe acute kidney injury during this study period. The induction chemotherapy regimen was CBDCA + PEM + BEV in 72 patients $(80 \%)$ and CBDCA + PEM in 18 (20\%) patients. At the start of induction chemotherapy, the concomitantly used drugs included NSAIDs in 18 patients (20\%), ARBs in 26 patients (29\%), ACEIs in 3 patients 
(3\%), aminoglycosides in 0 patients (0\%), and PPIs in 30 patients (33\%).

\section{Comparing two groups by the presence of positive correlation}

The rate of Scr change in an individual patient and the number of treatment courses in the $r_{+0.4<}$ and the $r_{+0.4 \geqq}$ groups are shown in the spider plot (Figs. 1 and 2). The $r_{+0.4<}$ group consisted of 49 patients [median value of $r$ (interquartile range), $+0.71(+0.60,+0.81)]$ and the $r_{+0.4 \geq}$ group comprised of 41 patients [median value of $r$, $+0.02(-0.29,+0.19)]$, and the regression formula of the $r_{+0.4<}$ group was $y=1.0164 x+4.2623$.

\section{Patient background information}

Table 1 presents the background information for the patients in the $r_{+0.4<}$ and the $r_{+0.4 \geqq}$ groups. The factors with a significance level of less than $5 \%$ were the median $\mathrm{cu}-$ mulative dose of PEM (interquartile range) $\left[r_{+0.4<}\right.$ group vs. $r_{+0.4 \geq}$ group, $9100(6365,12,260) \mathrm{mg} /$ body vs. 5600 (4140, 7440) $\mathrm{mg} /$ body, $P<0.01$ ] (Table 2); the number of patients concomitantly using NSAIDs at the start of treatment $\left[r_{+0.4<}\right.$ group vs. $r_{+0.4 \geqq}$ group, 15 patients (31\%) vs $3(7 \%), P<0.01]$; and the median number of treatment courses starting from induction chemotherapy $\left[r_{+0.4<}\right.$ group vs. $r_{+0.4 \geqq}$ group, $11(8,14)$ courses vs. $8(6,11)$ courses, $P<0.01]$.

\section{Univariate analysis and multivariate analyses}

For the three measurements that demonstrated a significance level of less than $5 \%$ in the comparison of patient background information, i.e., the cumulative dose of PEM, concomitant use of NSAIDs at the start of treatment, and the number of treatment courses starting from induction chemotherapy, we performed a univariate analysis with each measurement as an explanatory variable and the presence of a positive correlation as an objective variable. Furthermore, because the cumulative dose of PEM and the number of treatment courses starting from induction chemotherapy were on an ordinal scale, we calculated the predictive ability of the presence of a positive correlation and the cutoff value using a ROC curve $(7000 \mathrm{mg} /$ body, AUC $0.68, P<0.01 ; 10$ courses, AUC 0.71, $P<0.01$ ) (Fig. 3a, b). The results of the univariate analysis demonstrated a significant difference in all of the following: the cumulative dose of PEM $[\geqq 7000$ $\mathrm{mg} /$ body vs. $<7000 \mathrm{mg} /$ body, OR 2.92; $95 \%$ confidence interval (CI), 1.51-5.61, $P<0.01$ ], concomitant use of NSAIDs at the start of treatment (used vs. not used, OR 5.00; 95\% CI, 1.48-17.2, $P=0.01$ ), and the number of treatment courses starting from induction chemotherapy ( $\geqq 10$ courses vs. $<10$ courses, OR 1.88; 95\% CI, 1.04-3.39, $P=0.04)$. Next, assuming that the number of treatment courses starting from induction chemotherapy and the cumulative dose of PEM would be confounding in this analysis, the confounding effect was eliminated by excluding the number of treatment courses starting from induction chemotherapy as an explanatory variables, and the multivariate analysis of two measurements was performed. The results for the concomitant use of NSAIDs at the start of treatment and the cumulative dose of PEM analyzed by performing a multivariate analysis indicated that the cumulative dose of PEM was an independent explanatory variable (used vs. not used NSAIDs, OR 3.27, 95\% CI, $0.90-11.9, P=0.07$, and the cumulative dose of PEM $\geqq$ $7000 \mathrm{mg} /$ body vs. $<7000 \mathrm{mg} /$ body, OR 2.40, 95\% CI, 1.22 $4.75, P=0.01$, respectively) (Table 3 ).

\section{Incidence rate of BEV-induced proteinuria}

In this study, 37 patients (76\%) in the $r_{+0.4<}$ group and 35 (85\%) in the $r_{+0.4 \geq}$ group received treatment with a regimen including BEV. Among patients who received treatment with a BEV inclusive regimen, 14 patients $(38 \%)$ in the $r_{+0.4<}$ group and 6 patients (17\%) in the $r_{+0.4 \geq}$ group

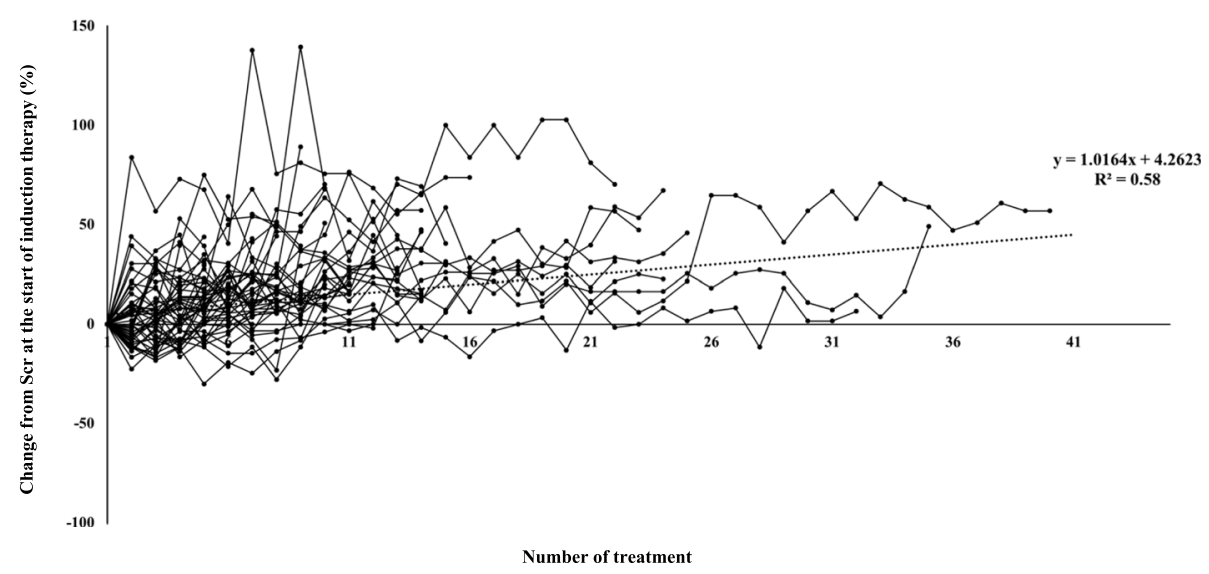

Fig. 1 Spider plot of individual patients Scr change rate with correlation coefficient $+0.4<$ Scr change rate: (Scr at start of induction therapy/Scr during study period) $\times 100$; Scr, serum creatinine level 


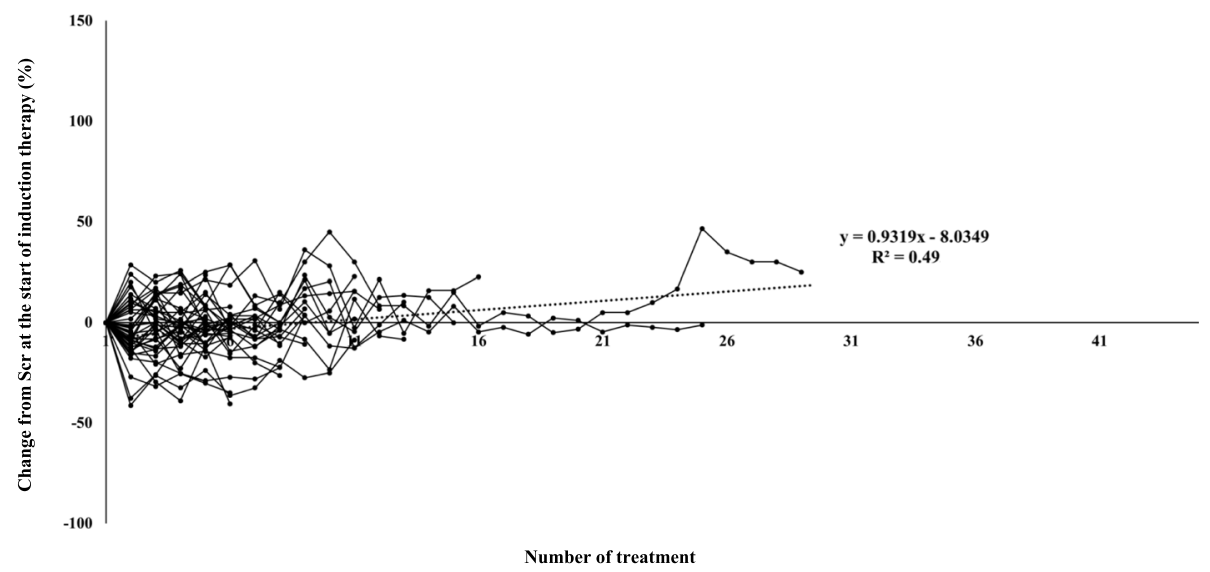

Fig. 2 Spider plot of Scr rate of change for patients with correlation coefficient $+0.4 \geqq$ Scr change rate: (Scr at start of induction therapy/Scr during study period) $\times 100$; Scr, serum creatinine level

were scored $1+$ or above in the qualitative proteinuria test, and there was no significant difference was observed between the two groups $(P=0.05)$. However, 10 patients (27\%) in the $r_{+0.4<}$ group and 2 patients $(6 \%)$ in the $r_{+0.4 \geqq}$ group were scored $2+$ or above, and the incidence rate in the qualitative proteinuria test in the $r_{+0.4<}$ group was significantly higher $(P=0.01)$ (Fig. 4). Patients whose treatment regimen excluded BEV were not administered qualitative proteinuria tests at this hospital and, hence, were not evaluated based on proteinuria.

\section{Safety}

Figure 5 shows the incidence rate of bone marrow suppression in the $r_{+0.4<}$ and the $r_{+0.4 \geqq}$ groups. A significant difference was observed in the rate of incidence of thrombocytopenia (grade 1 or above) between the $r_{+0.4<}$ and the $r_{+0.4 \geqq}$ groups [leukopenia, 18 patients (38\%) vs. 21 patients $(51 \%), P=0.17$; neutropenia, 22 patients (45\%) vs. 19 (47\%), $P=0.71$; anemia, 28 patients (57\%) vs. 30 patients $(73 \%), P=0.11$; thrombocytopenia, 9 patients $(18 \%)$ vs. 16 patients(39\%), $P=0.03$ ]. Additionally, no significant differences were observed in any measurements in the incidence rate of severe bone marrow suppression (grade 3 or above) [leukopenia, 1 patient (2\%) vs. 4 patients $(10 \%), P=$ 0.13 ; neutropenia, 4 patients (8\%) vs. 6 patients $(15 \%), P$

Table 2 Comparison of cumulative dose of anticancer drug (mg/body)

\begin{tabular}{llll}
\hline & $\boldsymbol{r}_{+\mathbf{0 . 4}<\boldsymbol{\prime}} \mathbf{N}=\mathbf{4 9}$ & $\boldsymbol{r}_{+\mathbf{0 . 4} \geq \boldsymbol{N}} \mathbf{N}=\mathbf{4 1}$ & $\boldsymbol{P}^{\text {a) }}$ \\
\hline CBDCA & $3200(2410,3,877)$ & $2500(2000,3,360)$ & 0.10 \\
PEM & $9100(6365,11,260)$ & $5600(4140,7,440)$ & $<0.01$ \\
BEV & $8250(4790,12,000)$ & $5510(4020,7,865)$ & 0.07 \\
\hline
\end{tabular}

Median (interquartile range)

CBDCA carboplatin, PEM pemetrexed, $B E V$ bevacizumab

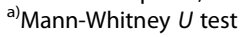

= 0.26; anemia, 1 patients (2\%) vs. 1 patients $(2 \%), P=$ 0.71 ; thrombocytopenia, 1 patients $(2 \%)$ vs. 1 patients (2\%), $P=0.71]$.

\section{Efficacy}

Figure 6 presents the Kaplan-Meier curve for the OS in the $r_{+0.4<}$ group and the $r_{+0.4 \geqq}$ group. The median OS in the $r_{+0.4<}$ group was 59.8 (range 6.4-75.0) months, which is significantly longer than the median OS of 38.7 (5.965.9) months in the $r_{+0.4 \geq}$ group $(P=0.04)$.

\section{Discussion}

The aim of this study was to evaluate the Scr of individual patients over time and determine whether long-term PEM exposure contributed to increased Scr. The results suggested that long-term exposure to PEM may cause chronic renal dysfunction in patients with non-squamous cell lung cancer.

The usefulness of maintenance therapy in the field of lung cancer has been explored in previous research. Specifically, the 2012 PARAMOUNT study has evaluated single-agent treatment with PEM [4], while Chen et al. [12], Middleton et al. [13], and Visser et al. [14] have reported renal dysfunction in patients who received PEM single-agent maintenance therapy. However, these studies did not investigate changes in the renal function of individual patients over time and, thus, did not report changes in the Scr of individual patients. Furthermore, although the AVAPERL trial [15] and the ECOG-ACRI N5508 trial [16] have indicated the usefulness of combining PEM with BEV when compared with PEM as a single-agent in maintenance therapy, no study has evaluated the changes in renal function over time in individual patients receiving combined PEM and BEV. Hence, the data regarding chronic renal failure in patients receiving long-term PEM are lacking. To address 
(A)

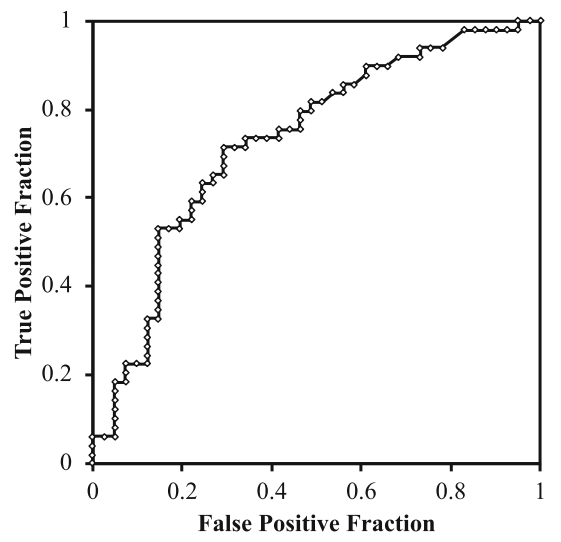

(B)

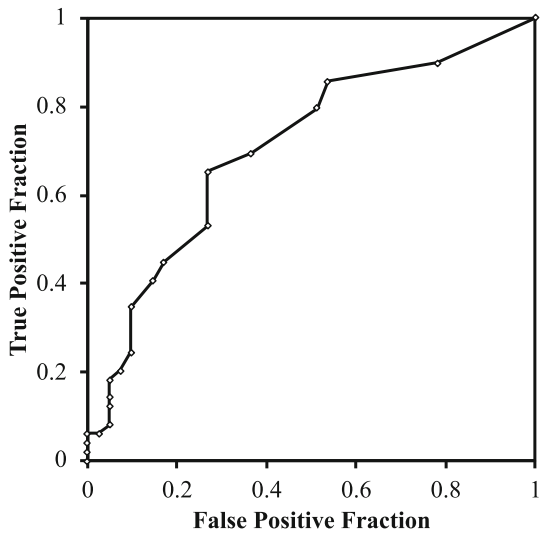

Fig. 3 a, b ROC curves of cumulative PEM dose (a) and number of courses from induction therapy (b). a Cutoff value $7000 \mathrm{mg} / \mathrm{body}$ (AUC 0.68, TPF 0.29, FPF 0.71, $P<0.01$ ). b Cut-off value 10 courses (AUC 0.71, TPF 0.27, FPF 0.65, $P<0.01$ ). PEM, pemetrexed; ROC, receiver operating characteristics; AUC, area under the curve; TPF, true positive fraction; FPF, false positive fraction

this issue, we performed a retrospective study to clarify the relationship between long-term PEM exposure and chronic renal damage, by investigating Scr changes over time in individual patients with non-squamous cell lung cancer who transitioned to $\mathrm{PEM} \pm \mathrm{BEV}$ maintenance therapy after receiving PEM $\pm \mathrm{BEV}$ induction chemotherapy combined with a platinum formulation.

A regression formula for the number of treatment courses and Scr rate of change in 49 patients (out of the original 90 evaluated patients), for whom the $r$ between the number of treatment courses and Scr was more the +0.4 , suggested that performing 10 treatments courses with PEM would produce a $+15 \%$ change in Scr. The maximum number of maintenance therapy courses was 44 in the PARAMOUNT trial [5], and the maximum number of treatment courses starting from induction therapy was 40 in our study. These previous studies suggest that the rate of Scr change could increase as the treatment continues, affecting treatment continuation and the performance of subsequent treatments.
In terms of risk factors for $r>+0.4$, the multivariate analysis demonstrated that a cumulative PEM dose of $7000 \mathrm{mg} /$ body or more was an independent factor, suggesting that long-term exposure to PEM may cause chronic renal dysfunction. Furthermore, a study has demonstrated that the use of NSAIDs is a risk factor for severe neutropenia induced by PEM [17], and this study indicated that NSAID use is a risk factor for $r>+0.4$. Hence, the concomitant use of NSAIDs in patients receiving long-term PEM treatment poses a risk for further chronic renal dysfunction and may lead to severe neutropenia.

This study examined not only PEM as a single-agent maintenance therapy, but also evaluated regimens including BEV, which included 72 of the 90 evaluated patients. However, no differences were observed in the proportion of concomitant BEV use or cumulative dose between the two groups, thus indicating that BEV demonstrated no effect on the increased Scr. Although no significant difference was observed in the incidence rate of proteinuria between the two groups, patients who were receiving a treatment regimen with $\mathrm{BEV}$ and were

Table 3 Binomial logistic regression analysis for correlation coefficient $+0.4<$ group

\begin{tabular}{|c|c|c|c|c|c|c|c|}
\hline & & \multicolumn{3}{|c|}{ Univariate analysis } & \multicolumn{3}{|c|}{ Multivariate analysis } \\
\hline & & Odds ratio & $\begin{array}{l}95 \% \text { confidence } \\
\text { interval }\end{array}$ & $P$ & Odds ratio & $\begin{array}{l}95 \% \text { confidence } \\
\text { interval }\end{array}$ & $P$ \\
\hline \multirow[t]{2}{*}{ NSAIDs } & With & 5.00 & {$[1.48-17.2]$} & 0.01 & 3.27 & {$[0.90-11.9]$} & 0.07 \\
\hline & Without & 1 & & & 1 & & \\
\hline \multirow[t]{2}{*}{ Number of treatments from induction therapy } & $\geqq 10$ & 1.88 & {$[1.04-3.39]$} & 0.04 & & & \\
\hline & $<10$ & 1 & & & & & \\
\hline \multirow[t]{2}{*}{ PEM cumulative dose (mg/body) } & $\geqq 7000$ & 2.92 & {$[1.51-5.61]$} & $<0.01$ & 2.40 & {$[1.22-4.75]$} & 0.01 \\
\hline & $<7000$ & 1 & & & 1 & & \\
\hline
\end{tabular}




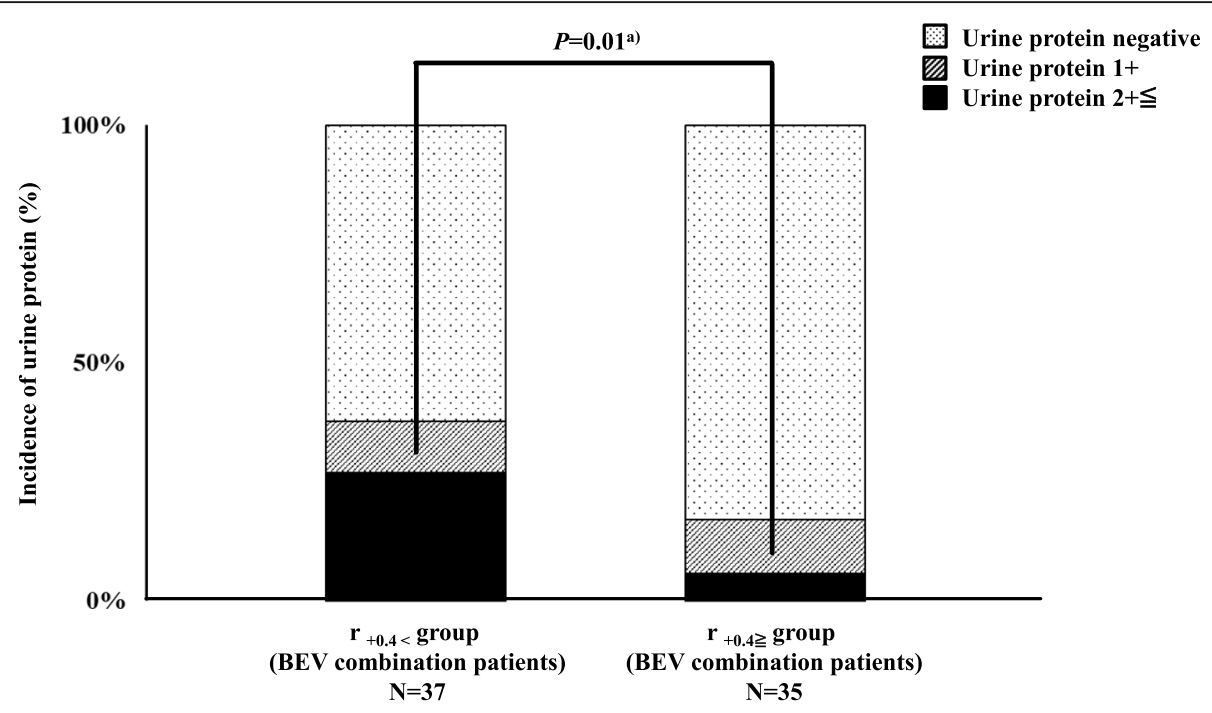

Fig. 4 Comparison of urine protein expression status between correlation coefficient $+0.4<$ group and correlation coefficient $+0.4 \geqq$ group in patients receiving $\mathrm{BEV}$ combination regimen. Presence or absence of urine protein $1+$ or higher: correlation coefficient $+0.4<$ group vs correlation coefficient $+0.4 \geqq$ group, $14(38 \%)$ vs $6(17 \%), P=0.05^{\mathrm{a}}$. Presence or absence of urinary protein $2+$ or higher: correlation coefficient + $0.4<$ group vs correlation coefficient $+0.4 \geqq$ group, $10(27 \%)$ vs $2(6 \%), P=0.01^{\text {a) }}{ }^{\text {a) }} x^{2}$ test. BEV, bevacizumab

in the $r_{>+0.4}$ group demonstrated a significantly higher incidence rate of $2+$ or more in the qualitative proteinuria test. Regarding the underlying mechanism of proteinuria attributed to $\mathrm{BEV}, \mathrm{BEV}$ inhibits the vascular endothelial growth factor involved in maintaining the function of glomerular capillary endothelial cells, resulting in decreased filtration function of the glomeruli, and the excretion of protein in the urine [18]. Patients in the $r_{>+0.4}$ group may present a high incidence rate of proteinuria and a high score of $2+$ or above in the qualitative proteinuria tests. This is because, although some urinary proteins are reabsorbed by the renal tubules, long-term PEM administration can cause tubular dysfunction and inhibit the reabsorption of protein from the urine, resulting in increased urinary protein. Reportedly, the incidence rate of nephrotic syndrome caused by severe long-term proteinuria in BEV treatment is less than $0.1 \%$. This study suggests that the increased Scr might not be markedly affected by the mild short-term proteinuria observed in this study, indicating that

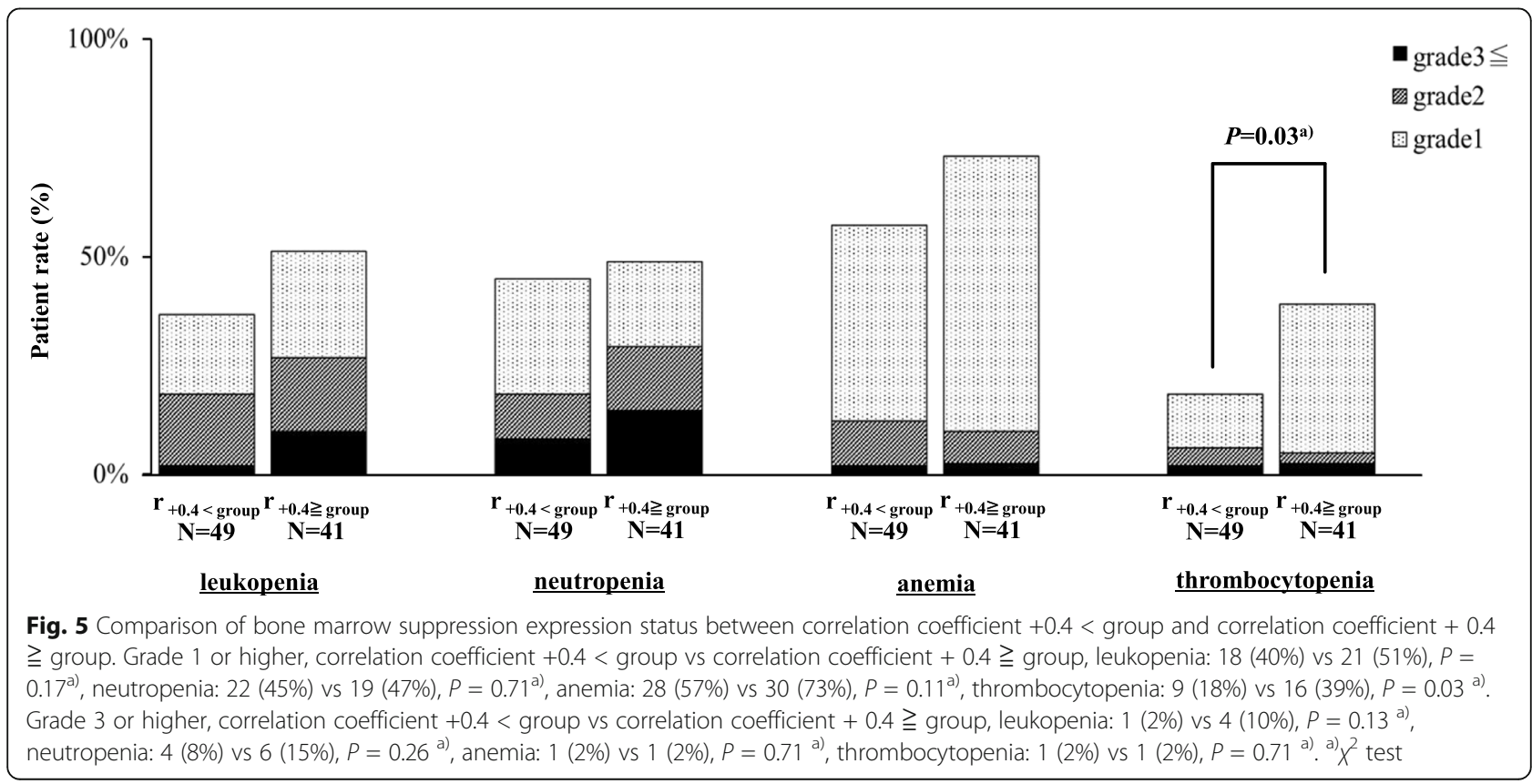




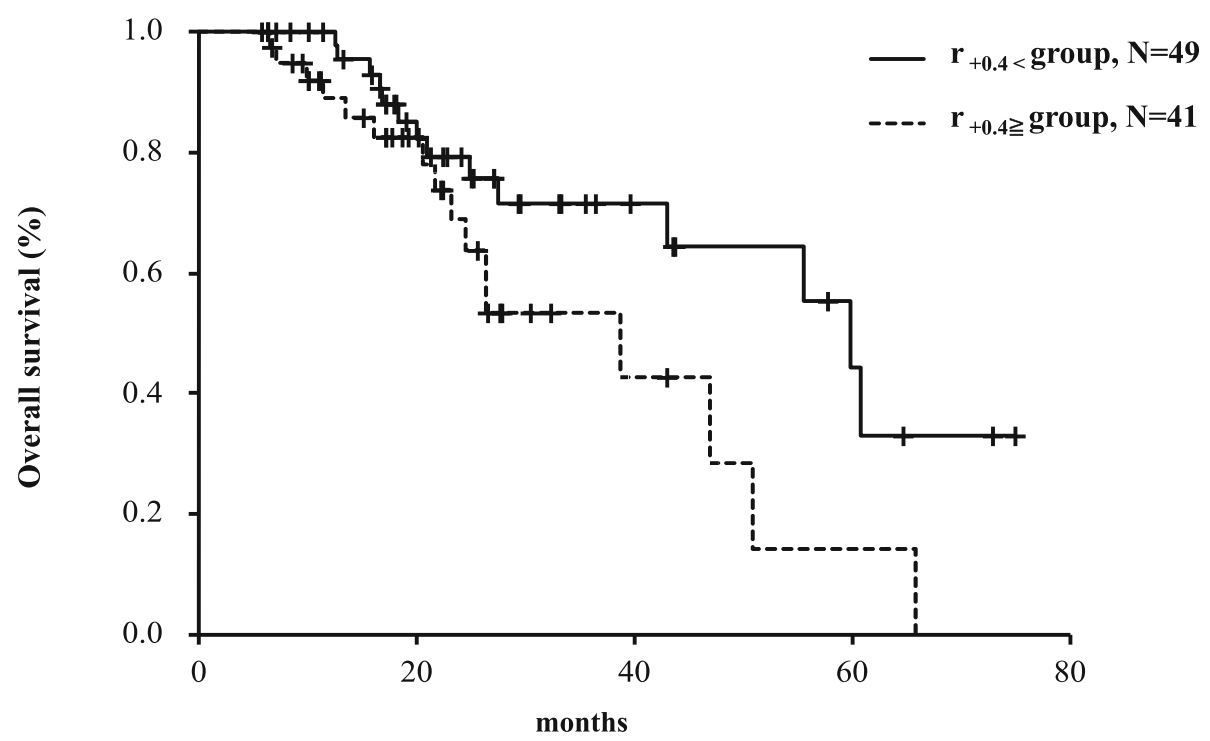

Fig. 6 Comparison of overall survival time between correlation coefficient $+0.4<$ group and correlation coefficient $+0.4 \geqq$ group. Correlation coefficient $+0.4<$ group vs correlation coefficient $+0.4 \geqq$ group, median 59.8 months (range, 6.4-75.0) vs median 38.7 months (range, 5.9-65.9), $P$ $=0.04$, Log-rank test

chronic increased Scr might be dependent on long-term exposure to PEM rather than BEV.

Notably, the median OS in these results was longer than the 16.9 months median OS starting from induction therapy as reported in the PARAMOUNT trial [5]. The effects of subsequent treatments in actual clinical settings, which differ from clinical trials, might contribute to the longer OS. The longer OS observed in the $r_{+0.4<}$ group than the $r_{+0.4 \geq}$ group was similar to the results documented by Chen et al. [12], which reported that the OS was longer in the group of patients with an eGFR less than $60 \mathrm{~mL} / \mathrm{min}$, indicating that the OS was longer in patients with decreased renal function. However, in this study, the number of treatment courses and cumulative doses of PEM in the $r_{+0.4<}$ group was higher than those in the $r_{+0.4 \geqq}$ group. This suggests that long-term PEM maintenance therapy may have prolonged the OS of patients. This study has not been able to identify the reasons for the shorter treatment duration in $r_{+0.4 \geqq}$ group and whether the association between renal function and survival rate, and why myelosuppression is less in the $r_{+0.4<}$ group than in the $r_{+0.4 \geqq}$ group. Regarding myelosuppression, the rate of thrombocytopenia of grade 1 or more was significantly higher in the $r_{+0.4 \geqq}$ group than in the $r_{+0.4<}$ group. On the other hand, the rate of grade 3 or more, which corresponds to the discontinuation criteria for PEM, was no difference between the two groups. It indicates that there is no relationship between myelosuppression and the treatment period.

A limitation of this study was the limited number of subjects evaluated from a single facility. Hence, these results cannot be generalized, and further multicenter studies are needed. There were no significant differences observed between the two groups regarding factors such as concomitant drugs affecting Scr, age, sex, and complications. However, as this was a retrospective study, we failed to possibly eliminate factors due to temporary changes in the patient condition such as dehydration. Scr is known to be affected by muscle mass. Renal function may be overestimated in older and smaller women and poorly nourished patients because they have less muscle mass and lower Scr production. For patients who are not suitable for assessment of renal function using Scr, the cystatin $\mathrm{C}$ method should be used to assess renal function, which is less sensitive to age and sex. In addition, the OS results in this study could not be compared to the efficacy of secondary treatments between the two groups. However, previous studies on kidney damage have reported acute kidney damage primarily due to tubular cell injury [9, $19,20]$, or increased blood concentration and intense side effects in cases of decreased kidney function as PEM is excreted by the kidneys $[6,21]$. To the best of our knowledge, the findings of this study are the first to confirm chronic renal dysfunction due to long-term PEM exposure. In recent years, the field of lung cancer has seen an increasing number of cancers survivors [22]. Chronic renal dysfunction may hinder patients from continuing treatment or transitioning to subsequent treatments. Since PEM administration may be a risk factor for chronic renal dysfunction in patients receiving long-term PEM therapy, maintaining kidney function during treatment by reducing the use of 
concomitant drugs and the risk of other renal dysfunctions, such as dehydration, may help patients continue treatment, resulting in long-term survival.

\section{Conclusions}

Long-term PEM exposure may induce chronic renal dysfunction. Hence, maintaining kidney function during PEM treatment by reducing the use of combination drugs and the risk of other renal dysfunctions, such as dehydration, may allow patients to continue therapy, thus contributing to long-term survival.

\section{Abbreviations}

ACEl: Angiotensin-converting-enzyme inhibitors; ARB: Angiotensin II receptor blockers; BEV: Bevacizumab; CBDCA: Carboplatin; Ccr: Creatinine clearance; Cl: Confidence interval; ECOG-PS: Eastern Cooperative Oncology Group Performance Status; NSAIDs: nonsteroidal anti-inflammatory drugs; OR: Odds ratio; OS: Overall survival; ROC: Receiver operating characteristic; PEM: Pemetrexed; PPI: Proton-pump inhibitors; Scr: Serum creatinine

\section{Acknowledgements}

Not applicable.

\section{Authors' contributions}

$\mathrm{KU}$ analyzed and interpreted the patient data. KY interpreted the patient data and was a major contributor in writing the manuscript. NK analyzed and interpreted the patient data. ST, AW, and TH interpreted the patient data. MK and HS interpreted the patient data and was a major contributor in writing the manuscript. All authors read and approved the final manuscript.

\section{Funding}

Not applicable.

\section{Availability of data and materials}

All data generated or analyzed during this study are included in this published article.

\section{Ethics approval and consent to participate}

This study was approved (approval no. 25-1) by the ethical review board of the Sapporo Minami-Sanjo Hospital in accordance with the Ethical Guidelines for Medical and Health Research Involving Human Subjects.

\section{Consent for publication}

Not applicable.

\section{Competing interests}

The authors declare that they have no competing interests.

\begin{abstract}
Author details
'Department of Pharmacy, National Hospital Organization Hokkaido Cancer Center, 2-3-54 Kikusui 4, Shiroishi-ku, Sapporo, Hokkaido 003-0804, Japan. ${ }^{2}$ Division of Clinical Pharmacy, Department of Pharmacy, Faculty of Pharmaceutical Sciences, Hokkaido University of Science, 15-4-1 Maeda 7, Teine-ku, Sapporo 006-8585, Japan. ${ }^{3}$ Pharmaceutical Division, Sapporo Minami-Ichijo Hospital (Hokkaido Keiaikai), 13-317-1 Minami 1, Chuo-ku, Sapporo, Hokkaido 060-0061, Japan. ${ }^{4}$ Pharmaceutical Division, Sapporo Minami-Sanjo Hospital (Hokkaido Keiaikai), 6-4-2 Minami 3, Chuo-ku, Sapporo, Hokkaido 060-0063, Japan. ${ }^{5}$ School of Pharmaceutical Sciences, Health Sciences University of Hokkaido, 1757 Kanazawa, Toubetsu-cho, Ishikari-gun, Hokkaido 061-0293, Japan.
\end{abstract}

Received: 6 April 2020 Accepted: 22 September 2020 Published online: 06 October 2020

\section{References}

1. Britten CD, Izbicka E, Hilsenbeck S, Lawrence R, Davidson K, Cerna C, et al. Activity of the multitargeted antifolate LY231514 in the human tumor cloning assay. Cancer Chemother Pharmacol. 1999;44:105-10. https://doi. org/10.1007/s002800050953.

2. Scagliotti GV, Parikh P, von Pawel J, Biesma B, Vansteenkiste J, Manegold C, et al. Phase III study comparing cisplatin plus gemcitabine with cisplatin plus pemetrexed in chemotherapy-naive patients with advanced-stage nonsmall-cell lung cancer. J Clin Oncol. 2008;26:3543-51. https://doi.org/10. 1200/JCO.2007.15.0375.

3. Scagliotti G, Hanna N, Fossella F, Sugarman K, Blatter J, Peterson P, et al. The differential efficacy of pemetrexed according to NSCLC histology: a review of two Phase III studies. Oncologist. 2009;14:253-63. https://doi.org/10.1634/ theoncologist.2008-0232

4. Paz-Ares L, de Marinis F, Dediu M, Thomas M, Pujol JL, Bidoli P, et al. Maintenance therapy with pemetrexed plus best supportive care versus placebo plus best supportive care after induction therapy with pemetrexed plus cisplatin for advanced non-squamous non-small-cell lung cancer (PARA MOUNT): a double-blind, phase 3, randomised controlled trial. Lancet Oncol. 2012;13:247-55. https://doi.org/10.1016/S1470-2045(12)70063-3.

5. Paz-Ares LG, de Marinis F, Dediu M, Thomas M, Pujol JL, Bidoli $P$, et al. PARAMOUNT: Final overall survival results of the phase III study of maintenance pemetrexed versus placebo immediately after induction treatment with pemetrexed plus cisplatin for advanced nonsquamous non-small-cell lung cancer. J Clin Oncol. 2013;31:2895-902. https://doi. org/10.1200/JCO.2012.47.1102.

6. Mita AC, Sweeney CJ, Baker SD, Goetz A, Hammond LA, Patnaik A, et al. Phase I and pharmacokinetic study of pemetrexed administered every 3 weeks to advanced cancer patients with normal and impaired renal function. J Clin Oncol. 2006;24:552-62. https://doi.org/10.1200/JCO.2004.00.9720.

7. Hanna N, Shepherd FA, Fossella FV, Pereira JR, De Marinis F, von Pawel J, et al. Randomized phase III trial of pemetrexed versus docetaxel in patients with non-small-cell lung cancer previously treated with chemotherapy. J Clin Oncol. 2004;22:1589-97. https://doi.org/10.1200/JCO.2004.08.163.

8. Perazella MA. Onco-nephrology: renal toxicities of chemotherapeutic agents. Clin J Am Soc Nephrol. 2012;7:1713-21. https://doi.org/10.2215/CJN.02780312.

9. Shih C, Chen VJ, Gossett LS, Gates SB, MacKellar WC, Habeck LL, et al. LY231514, a pyrrolo [2,3-d] pyrimidine-based antifolate that inhibits multiple folate-requiring enzymes. Cancer Res. 1997;57:1116-23.

10. Glezerman IG, Pietanza MC, Miller V, Seshan SV. Kidney tubular toxicity of maintenance pemetrexed therapy. Am J Kidney Dis. 2011;58:817-20. https:// doi.org/10.1053/j.ajkd.2011.04.030.

11. Vootukuru V, Liew YP, Nally JV Jr. Pemetrexed-induced acute renal failure, nephrogenic diabetes insipidus, and renal tubular acidosis in a patient with non-small cell lung cancer. Med Oncol. 2006;23:419-22. https://doi.org/10. 1385/MO:23:3:419.

12. Chen CY, Lin JW, Huang JW, Chen KY, Shih JY, Yu CJ, et al. Estimated creatinine clearance rate is associated with the treatment effectiveness and toxicity of pemetrexed as continuation maintenance therapy for advanced nonsquamous non-small-cell lung cancer. Clin Lung Cancer. 2015;16:e13140. https://doi.org/10.1016/j.cllc.2015.01.001.

13. Middleton G, Gridelli C, De Marinis F, Pujol JL, Reck M, Ramlau R, et al. Evaluation of changes in renal function in PARAMOUNT: a phase III study of maintenance pemetrexed plus best supportive care versus placebo plus best supportive care after induction treatment with pemetrexed plus cisplatin for advanced nonsquamous non-small-cell lung cancer. Curr Med Res Opin. 2018;34:865-71. https://doi.org/10.1080/03007995.2018.1439462.

14. Visser S, Huisbrink J, van 't Veer NE, van Toor JJ, van Boxem AJM, van Walree NC, et al. Renal impairment during pemetrexed maintenance in patients with advanced nonsmall cell lung cancer: a cohort study. Eur Respir J. 2018;52:pii:1800884. doi: 10.1183/13993003.00884-2018.

15. Barlesi F, Scherpereel A, Gorbunova V, Gervais R, Vikström A, Chouaid C, et al. Maintenance bevacizumab-pemetrexed after first-line cisplatinpemetrexed-bevacizumab for advanced nonsquamous nonsmall-cell lung cancer: updated survival analysis of the AVAPERL (MO22089) randomized phase III trial. Ann Oncol. 2014;25:1044-52. https://doi.org/10.1093/annonc/ mdu098.

16. Ramalingam SS, Dahlberg SE, Belani CP, Saltzman JN, Pennell NA, Nambudiri GS, et al. Pemetrexed, bevacizumab, or the combination as maintenance therapy for advanced nonsquamous non-small-cell lung cancer: ECOG-ACRI N 5508. J Clin Oncol. 2019;37:2360-7. https://doi.org/10.1200/JCO.19.01006.

17. Kawazoe H, Yano A, Ishida Y, Takechi K, Katayama H, Ito R, et al. Nonsteroidal anti-inflammatory drugs induce severe hematologic toxicities in lung cancer patients receiving pemetrexed plus carboplatin: A retrospective 
cohort study. PLoS One. 2017;12:e0171066. https://doi.org/10.1371/journal. pone. 0171066 .

18. Saif MW, Mehra R. Incidence and management of bevacizumab-related toxicities in colorectal cancer. Expert Opin Drug Saf. 2006;5:553-66. https:// doi.org/10.1517/14740338.5.4.553.

19. Assayag M, Rouvier P, Gauthier M, Costel G, Cluzel P, Mercadal L, et al. Renal failure during chemotherapy: renal biopsy for assessing subacute nephrotoxicity of pemetrexed. BMC Cancer. 2017;17:770. https://doi.org/10. 1186/s12885-017-3705-7.

20. Sbitti Y, Chahdi H, Slimani K, Debbagh A, Mokhlis A, Albouzidi A, et al. Renal damage induced by pemetrexed causing drug discontinuation: a case report and review of the literature. J Med Case Rep. 2017;11:182. https://doi. org/10.1186/s13256-017-1348-6.

21. Latz JE, Chaudhary A, Ghosh A, Johnson RD. Population pharmacokinetic analysis of ten phase II clinical trials of pemetrexed in cancer patients. Cancer Chemother Pharmacol. 2006;57:401-11. https://doi.org/10.1007/ s00280-005-0036-1.

22. Ito Y, Miyashiro I, Ito H, Hosono S, Chihara D, Nakata-Yamada K, et al. Longterm survival and conditional survival of cancer patients in Japan using population-based cancer registry data. the J-CANSIS Research Group. Cancer Science. 2014;105:1480-6. https://doi.org/10.1111/cas.12525.

\section{Publisher's Note}

Springer Nature remains neutral with regard to jurisdictional claims in published maps and institutional affiliations.

Ready to submit your research? Choose BMC and benefit from:

- fast, convenient online submission

- thorough peer review by experienced researchers in your field

- rapid publication on acceptance

- support for research data, including large and complex data types

- gold Open Access which fosters wider collaboration and increased citations

- maximum visibility for your research: over $100 \mathrm{M}$ website views per year

At BMC, research is always in progress.

Learn more biomedcentral.com/submissions 